Journal of

Accident and

Emergency

Medicine 1995

12, 291-292

\title{
Near asphyxiation with a child's dummy
}

\author{
A.F. MACNAMARA \& S. DURHAM
}

Accident and Emergency Department, Leicester Royal Infirmary, Infirmary Road, Leicester, UK

\section{SUMMARY}

A case is reported of near asphyxiation in a child caused by impaction of a dummy in the upper airway. Previous similar cases are described and recommendations made for changes in the design of children's dummies to improve their safety profile.

Key words: child's dummy, asphyxiation

\section{CASE REPORT}

A 1-year-old child was brought to the accident and emergency (A\&E) department with a dummy that had accidentally lodged in his throat while he was in bed. The child's parents had tried to remove the dummy with their fingers and by holding the child upside down. Attempts by ambulance staff to remove the dummy were also unsuccessful.

On arrival at the A\&E department the child was cyanosed and making poor quality and noisy respiratory efforts. He was noted to be bradycardic with a pulse of $60 \mathrm{bpm}$. The dummy was stuck in his throat with the teat facing forwards and the flange stuck between the nasopharynx superiorly and the vallecula of the tongue inferiorly (Fig. 1), in a similar fashion to that described by Williams. ${ }^{1}$ It was removed with difficulty by a combination of rotation and traction with the fingers. The child sustained a small laceration to the soft palate during the procedure, but rapidly became pink and fully alert, with a pulse of $90 \mathrm{bpm}$.

\section{THE DUMMY}

A. MacNamara, Registrar, Accident and Emergency Department, Leicester Royal Infirmary, Infirmary Road, Leicester, UK the flange of the dummy must have two ventilation holes which allow the passage of a $5 \mathrm{~mm}$ diameter rod and that 'these two ventilation holes should be symmetrically located on the flange'. The presence of further ventilation holes on the flange are optional. The dummy in this case conformed to the current British Standard in both these regards (Fig. 2).

\section{COMMENT}

Unlike a previous case, ${ }^{1}$ the ventilation holes in the flange of the dummy did not allow the child to breathe satisfactorily and in effect his upper airway was occluded by the position of the dummy (Fig. 1) Another previous case report ${ }^{3}$ suggested enlarging the size of the flange on dummies to prevent them accidentally entering the oral cavity.

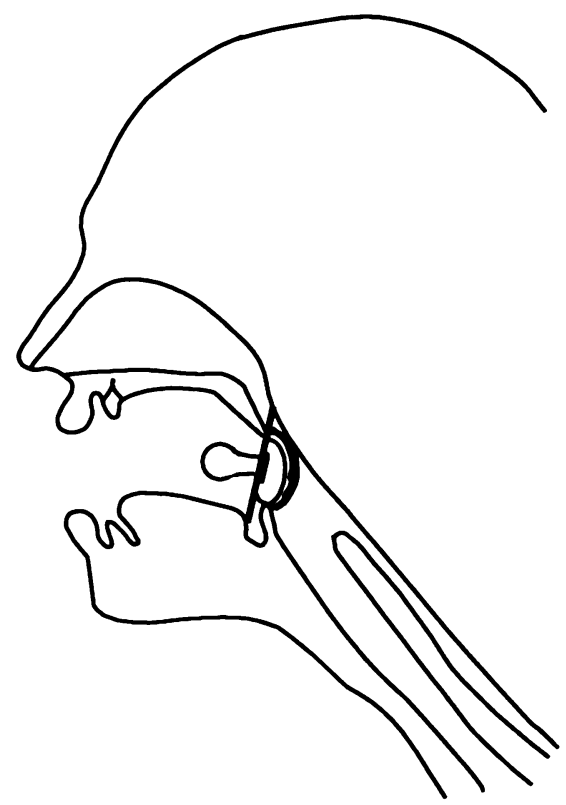

Fig. 1. Position of impaction of the dummy.

(C) 1995 Blackwell Science Ltd 
A.F. MacNamara \&

S. Durham

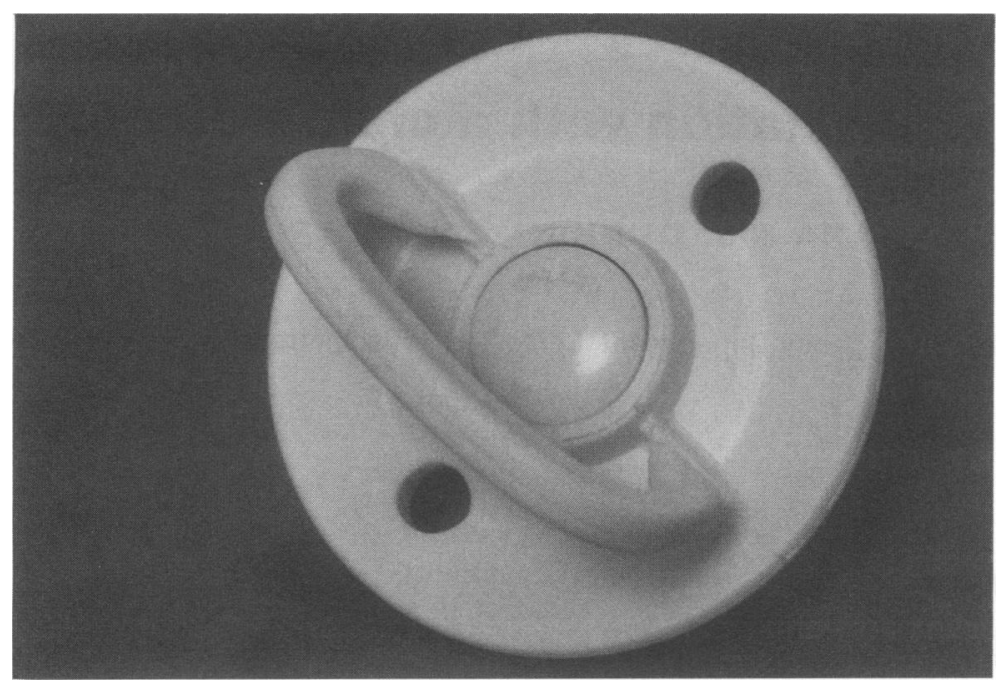

Fig. 2. Dummy and ventilation holes.
We support this recommendation to the British Standards Institute.

The two standard ventilation holes are usually sited diametrically opposed to each other on the flange. It is our feeling that if one ventilation hole is obstructed by the position in which the flange becomes impacted, then the other ventilation hole lies directly opposite and is similarly likely to become obstructed. We therefore suggest that it should be mandatory to have more than two ventilation holes in children's dummies and that if these were spaced around the flange it would be less likely for them all to become obstructed, as happened in this case.

It has been postulated elsewhere ${ }^{4}$ that the use of dummies may help protect against sudden infant death syndrome, but until the design of children's dummies is made safer their use for this purpose cannot be recommended.

\section{REFERENCES}

1. Williams M.J. (1991) The need for ventilation holes in children's dummies. Archives of Emergency Medicine 8, 59-62.

2. BSI (1988) British Standard specification for babies dummies. BS 5239 (1988). British Standards Institution, London.

3. Clayton M.G., Atkinson J.R. \& Isaacs G. (1987) Asphyxiation by a child's dummy. British Medical Journal 295, 1098.

4. Mitchell E.A., Taylor B.J. \& Ford R.P.K. et al. Dummies and the sudden infant death syndrome. Archives of Disease in Childhood 68, 501-504. 